\title{
RINALDI, Alessandra de Andrade. A sexualização do crime no Brasil: um estudo sobre criminalidade feminina no contexto de relações amorosas (1890-1940). Rio de Janeiro: Mauad X/ Faperj, 2015, 222p. \\ Bruna ANgOtTI
}

Universidade de São Paulo, São Paulo, São Paulo, Brasil

DoI 10.11606/issn.2316-9133.v25i25p469-474

Refletir sobre delineações da criminalidade feminina e suas especificidades nas últimas décadas do século XIX e primeiras do XX é tarefa de primeira importância para se compreender os padrões que pautaram as expectativas sobre o comportamento de mulheres e, consequentemente, o desvio, no período que antecedeu a legislação penal atualmente vigente. De certo modo é esse o exercício feito pela antropóloga Alessandra de Andrade Rinaldi em seu estudo $A$ sexualização do crime no Brasil: um estudo sobre criminalidade feminina no contexto de relações amorosas (1890-1940), focado especificamente em acusações de crimes perpetrados por mulheres contra seus cônjuges, amásios ou rivais.

Por meio de cuidadoso levantamento documental do período em questão, a autora recuperou "quarenta processos criminais; dois 'laudos' médico-legais; um 'parecer' avaliando um pedido de diminuição de pena; uma decisão de uma 'apelação criminal' encaminhada à Corte de Apelação do Rio de Janeiro” (p. 31) referentes a casos envolvendo lesão corporal, homicídio e/ou tentativa de homicídio que tinham como rés mulheres acusadas em cenários de relações amorosas. Seu objetivo central era compreender "como, na prática, os profissionais do campo jurídico da época pensavam e julgavam crimes femininos em contextos de relações amorosas", bem como "apreender a importância dos contornos morais construídos por acusadas, vítimas e testemunhas em âmbito processual e a prática de compreensão e avaliação dos juristas sobre esses crimes” (p. 14).

Em um momento no qual se apontava para a ascensão da criminalidade feminina, e em que a questão era debatida por especialistas tanto no Brasil quanto em outros países, como França e Itália, os contornos da delinquência feminina tomavam forma. Pelas penas de criminólogos, juristas e agentes do direito, bem como nas formulações advindas do senso comum, produzia-se saber acerca das mulheres delinquentes, dos tipos de delitos por elas cometidos e das razões 
que as levavam a delinquir. Assim, mostra-se acertada a escolha da autora pelo recorte temporal de 1890 a 1940, quando estava em pauta entender como, no cotidiano do Sistema de Justiça, esses saberes eram agenciados e também produzidos pela defesa, acusação, julgadores, testemunhas e partes de casos envolvendo violência no contexto das relações amorosas. A autora também justifica o recorte temporal pelo surgimento, a partir da década de 1920, do termo "crime passional”.

Ainda, para dar conta de "apreender como, ao ser discutida a criminalidade feminina, cruzavam-se as produções médicas sobre o feminino e as jurídicas sobre o crime" (p. 14), Rinaldi levanta a produção científica acerca da criminalidade feminina assinada por especialistas das áreas médicas e jurídicas publicada em periódicos científicos da época.

A obra está dividida em duas partes, compostas por dois capítulos cada. $\mathrm{Na}$ "Parte I", a autora apresenta a produção de saberes acerca da criminalidade feminina, expondo, no primeiro capítulo, discussões europeias e nacionais sobre o crime em geral e, especialmente, o crime feminino. Para tanto, apresenta o debate entre as duas principais teorias criminológicas em voga na segunda metade do século XIX, quais sejam, a Escola Clássica - que atribuía a conduta criminosa ao livre-arbítrio e à escolha racional - e a Escola Positivista - para quem a etiologia do crime estava na composição biológica do sujeito delinquente. Retomar tal discussão é indispensável quando está em pauta a construção científica acerca da criminalidade e o papel dos saberes médicos e jurídicos nesse processo no ocaso do século XIX e início do XX, como feito também no Brasil, por exemplo, por Ferla (2009) e Schwarcz (2008).

Ainda no primeiro capítulo, a autora reconstrói o surgimento e o uso da categoria "crime passional" no contexto jurídico brasileiro, mostrando a influência da Escola Positivista, em especial da teoria do criminólogo italiano Enrico Ferri, e de teorias cientificistas nessa categorização. Tratava-se de "uma categoria não codificada em termos legais e, na prática, julgada por meio da dirimente 'perturbação dos sentidos e da inteligência”, usada para condenar e absolver acusados e acusadas de violências no âmbito conjugal (p. 15). O jogo jurídico em casos nos quais se alegava tratar-se de um crime passional passava pela discussão acerca da inimputabilidade penal, daqueles que tiveram sua honra ultrajada e, portanto, encontravam-se sob os perturbadores efeitos da paixão nos sentidos.

Já no segundo capítulo, Rinaldi destaca como a ciência médica e jurídica da época teceu uma relação íntima entre a mulher criminosa e a natureza feminina, especialmente associada aos órgãos do sistema reprodutivo e ao seu (bom ou mau) funcionamento. A autora recupera a genealogia feita pelo filósofo Thomas Laqueur na obra Inventando o sexo: corpo e gênero dos gregos a Freud para mostrar como o modelo de dois sexos, delineado pelas ciências médicas a partir do século XVIII, pautou a diferença entre os gêneros. Ao definir o corpo do ho- 
mem e da mulher como corpos biologicamente distintos, a ciência naturalizou as diferenças comportamentais, imputando os gêneros masculino e feminino respectivamente aos corpos de homens e mulheres, radicalizando a diferença e a hierarquização entre eles. O corpo feminino passou a ser visto como lugar da patologia, dos excessos hormonais e endócrinos, e a mulher, reduzida a uma existência guiada pelos humores e regrada pelo seu sistema reprodutivo. Em seguida a autora aborda, por meio de artigos científicos do período, como se deu no Brasil a associação entre natureza feminina e crime, mostrando a influência no pensamento nacional das teorias em voga na Europa.

É na "Parte II", composta pelo terceiro e quarto capítulos, que se encontra o ápice da obra ora resenhada. Isso porque é nela que a autora apresenta e analisa detalhadamente fragmentos dos documentos pesquisados, trazendo como contribuição ao campo dos estudos sobre criminalidade feminina a identificação dos processos de construção desta, por meio de discursos de diferentes ordens que, ainda que divergentes, conviviam entre si, nas defesas, acusações e sentenças, esboçando perfis da delinquência feminina no período.

No "Capítulo 3", Rinaldi trabalha com excertos de depoimentos de acusadas, testemunhas e vítimas, buscando "padrões de moralidade recorrentes" (p. 105) a partir dos quais se podem identificar "quatro grandes eixos argumentativos em torno dos quais circularam a construção dos motivos para que mulheres cometessem crimes em contextos de relações amorosas" (p. 106). Compõem esses eixos motivos relacionados a situações nas quais as relações amorosas estavam sob ameaça; a desavenças com relação ao desempenho das obrigações conjugais e domésticas; a atentados contra a honra feminina e a necessidade de restaurá-la; a avaliações externas feitas por especialistas ou outros sobre o ato e sobre a acusada, que contribuem para a construção da figura da "criminosa-louca" ou da "louca-criminosa". Partindo da ideia de "causas socialmente relevantes" usada pelo antropólogo Evans-Pritchard em Bruxaria, oráculos e magia entre os Azande, a autora trabalha com "causas moralmente relevantes" para identificar quais razões justificavam o delito ou reforçavam seu caráter negativo. Ainda nesse capítulo, Rinaldi utiliza a ideia, trabalhada pela antropóloga Adriana Vianna, de que há nos argumentos utilizados um cálculo de repercussão segundo o qual os atores buscavam "ao se pronunciar perante os representantes do direito, [...] construir contornos morais ideais” (p. 103).

Já no quarto e último capítulo, Rinaldi apresenta os principais argumentos utilizados pelos agentes do direito para justificar ou reprovar a violência feminina, identificando três eixos argumentativos: o da moralidade, o jurídico e o científico. O agenciamento de argumentos relacionados a esses eixos dependia de uma série de fatores, como perfil da acusada e da vítima, delito cometido, circunstâncias do crime. A autora ressalta o peso dado, nos documentos estudados, à avaliação do comportamento feminino, uma vez que a todo o tempo critérios 
morais relacionados à conduta feminina pautam as argumentações. Ser honesta era um valor importante nos autos e pesava de maneira positiva em favor das mulheres. Ao contrário, ser vingativa, provocadora ou estar fora do ideal feminino esperado era negativo. $\mathrm{O}$ uso de categorias doutrinárias-jurídicas, por sua vez, era feito estrategicamente, em especial quando as questões morais precisavam ser silenciadas, dado o perfil "desviante" da ré ou do acusado. Por fim, as alegações de ordem científica surgiam especialmente em casos nos quais se buscava o reconhecimento de inimputabilidade da ré, por razões de responsabilidade reduzida, situações nas quais a categoria crime passional era ativada. A mulher que cometia crime passional era geralmente vista como criminosa ocasional, sujeita às intempéries da paixão, e não como degenerada e louca.

Ana Lúcia Pastore Schritzmeyer identifica em seu estudo sobre tribunal do júri que nas sessões de júri está em jogo principalmente a legitimidade ou ilegitimidade do ato: "dependendo de como as mortes são contadas, imaginadas e transformadas em imagens a serem julgadas, possíveis usos do poder de matar são socialmente legitimados ou não" (SCHRITZMEYER, 2012, p. 49). O estudo de Rinaldi identifica algo semelhante - a violência perpetrada é menos relevante que as razões alegadas para ela, sendo fundamental a maneira como são justificadas para garantir resultados de absolvição e ou condenação para as rés. Estava também em jogo nos casos analisados pela pesquisadora a legitimidade social atribuída às violências perpetradas, e, nesse contexto, a escolha minuciosa dos argumentos e da elaboração da narrativa tinha peso importante na legitimação ou não da violência praticada.

Em termos metodológicos, vale destacar que a autora traz uma contribuição importante para os estudos que utilizam autos processuais como fontes primárias na área da antropologia. Isso porque, ao analisar os depoimentos dos envolvidos no processo, bem como os argumentos da defesa, da acusação e dos magistrados, Rinaldi agrupa em eixos diferentes o teor das motivações e das alegações, permitindo não somente olhar os autos como um todo, mas, principalmente, desmembrá-los em conjuntos que requerem análises específicas. Ao usar o critério do agrupamento como recurso metodológico, a autora faz os documentos dialogarem entre si, possibilitando a criação de categorias analíticas que potencializam o uso das peças jurídicas estudadas.

Outro mérito do trabalho é, logo na "Apresentação", fazer um balanço do campo dos estudos sobre violência, gênero e crime passional no Brasil, referenciando estudos pioneiros na área da antropologia, sociologia e história. A autora situa seu trabalho entre aqueles que se propõem a olhar para as mulheres não na chave da passividade e da vitimização, mas buscando compreender "como o campo jurídico nacional julgava mulheres criminosas. Como as pensava nos casos de crimes cometidos em contextos das relações amorosas” (p. 25). Tal opção se deu justamente com o intuito de produzir conhecimento acerca do "trata- 
mento jurídico dado aos crimes femininos" (p. 25), contribuindo para ampliar o entendimento acerca da questão de modo a não reduzir o debate a estereótipos pré-determinados.

Conforme proposto por Virgínia Woolf no ensaio A paixão da leitura, ao realizar pela primeira vez a leitura de uma obra, devemos ser "cúmplices do escritor", sendo "nossa primeira obrigação como leitores tentar entender o que o escritor está fazendo, desde a primeira palavra com que compõe a primeira frase até a última com que termina o livro" (WOOLF, 2015, p. 36). Em seguida, em um momento pós-leitura, Woolf propõe que "o leitor deve deixar o banco dos réus e se acomodar na poltrona do juiz" (WOOLF, 2015, p. 36), encarando então o livro como um todo, comparando-o com outros, avaliando-o em relação a um conjunto mais amplo.

Inspirada por Woolf, busquei seguir esses passos na leitura da obra de Alessandra Rinaldi. Primeiramente dei a mão à autora e a deixei conduzir-me pelos meandros jurídicos, médicos e científicos que pautavam o debate sobre criminalidade feminina na virada do século XIX para o XX, atendo-me aos detalhes dos casos e das histórias narradas na segunda parte do trabalho. A autora, ao trazer ao texto excertos dos documentos jurídicos pesquisados, deu vida a histórias há muito encerradas, permitindo ao leitor um passeio investigativo pelas pretorias criminais do Rio de Janeiro, em um momento no qual a discussão sobre a criminalidade feminina e crimes passionais estava em voga.

Ao término da leitura, seguindo então o segundo passo proposto por Woolf, tive clareza de que se trata de um trabalho na área da antropologia do direito que muito contribui para os estudos sobre criminalidade feminina em geral e, especialmente, nos contextos das relações amorosas. O trabalho de Rinaldi, além de servir como modelo interessante para quem pretende se aventurar pela análise de autos processuais, também serve como inspiração para pesquisas documentais na área da antropologia, mostrando o quão profícuo pode ser um trabalho na interface da antropologia com a história. Nos tempos atuais, com o aumento vertiginoso do encarceramento de mulheres, a análise feita por Rinaldi traz insumos importantes para a produção de conhecimento sobre a compreensão acerca da criminalidade feminina e sua relação com o Sistema de Justiça.

\section{Referências bibliográficas}

FERLA, Luis. Feios, sujos e malvados sob medida: a utopia médica do biodeterminismo. São Paulo: Alameda, 2009.

SCHWARCZ, Lilia Moritz. O espetáculo das raças. Cientistas, instituições e questão racial no Brasil (1870-1930). São Paulo: Companhia das letras, 2008.

SCHRITZMEYER, Ana Lícia Pastore. Jogo, ritual e teatro: um estudo antropoló- 
474 | BRUnA ANGotTI

gico do tribunal do júri. São Paulo: Terceiro nome, 2012.

WOOLF, Virginia. A paixão da leitura. In: O sol e o peixe: prosas poéticas. Belo Horizonte: Autêntica, 2015. p. 35-39.

\section{autora Bruna Angotti}

Mestra e Doutoranda em Antropologia Social pela Universidade de São Paulo (USP), professora do curso de Direito da Universidade Presbiteriana Mackenzie, pesquisadora do Núcleo de Antropologia do Direito (Nadir)

Recebido em 17/12/2016

Aceito para publicação em 09/01/2017 